\title{
Long Term Winter Season 2017/2018 Northern Hemisophere and Their Impact over Indonesia Maritime Continent Area
}

\author{
Paulus Agus Winarso* \\ State College Meteorology Climatology and Geophysics, Indonesia
}

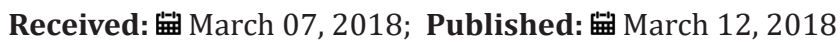

*Corresponding author: Paulus Agus Winarso, State College Meteorology Climatology and Geophysics, Indonesia

\section{Short Communication}

The winter season 2017/2018 could be one of the unusual condition with increasing the winter storm activities over Northern Hemisphere to affect aerodrome closed for certain airports in big city of the United States of America and Canada in Northern America Continent, it could be over European Countries and North Asian Continent. The freezing water Niagara for the first time during last 50 years could be additional condition from coolest than normal and it might longer than usual based upon public information and collecting the global climatic chart from National Climate Centers under coordination from the World Meteorological Organization. If the condition winter season 2017/2018 compared with previous condition especially in the 17 years or it could be more than that period, the winter season $2017 / 2018$ could be worst condition and situation especially with winter storm occurrences over most northern hemisphere. Reversal condition over southern hemisphere with summer season with few day occurrences of the heat wave over Australia continent last January 2018. To assess the weather and climatic over the earth's surface that weather and climate development came from uneven solar radiation (solar activities) received by the earth's surface, it meant that solar radiation could consider as the main subject to asses/study the global circulation over lower atmosphere of the earth. Where we could consider solar radiation to have closed relation with solar activities in term of the sunspot and solar flare to investigate how much solar radiation/ energy emits from the center of the solar system.

In this case, the sunspot number counted every month could be used as the quantity and quality sun radiation/energy with high number of sunspot to represented large sun radiation received by the earth surface to the universe of the earth - sun system. It could also be with small number of sunspot with respect with the time especially daily, weekly, monthly, seasonally up to yearly basis to be represent less of the sun radiation received by the earth surface. From further assessment and study of the sunspot number has a relation with the weather and climate condition over the earth surface especially formation of the global air circulation both north - south between equator - north and south poles and east - west direction over the equator. High or maximum number of the sunspot on the monthly basis for $6-12$ months duration could encourage global phenomena of the El Nino (warming sea surface temperature over equator east Pacific Ocean) and small or minimum number of the sunspot could encourage reversal El Nino in term of the La Nina. Both of the global phenomena would affect certain weather and climatic condition globally arising unusual weather and climatic pattern over the earth's surface.

Based on the sunspot number on the monthly basis could be arranged in term of the sunspot cycle to represent from minimum number toward maximum as the peak sunspot number then to be going down toward minimum number. Now, there 24 sunspot cycles with one cycle having duration at about 11 years. It means every sunspot cycle has period between $10-12$ years. At this period 2017/2018, sunspot cycle number 24 would be toward small number of minimum of the sunspot or minimum sun's radiation received by the earth surface. Such that La Nina episode would active starting middle of the year 2016 up to beginning 2018. Where La Nina episode has large contribution in the developing equatorial wave of the so called Madden Julian Oscillation (MJO) which create intra seasonal weather and climatic condition over the tropical area especially over Indian Ocean Indonesia Maritime Continent and West Pacific Ocean. During MJO passing over the consecutive areas Indian Ocean - West Pacific Ocean, array of the large tower of cumulonimbus cloud would be active to support the tropical cyclone formation and other local storm. Beside the global perspective, there would be regional perspective phenomena coincide with Asian winter monsoon activities in terms of the cold surge to form the Borneo Vortex mostly over west Indonesia Maritime Continent. With having long period and cooler condition 
during winter season 2017/2018, the Borneo Vortex frequently forms during lack MJO activities or when MJO move eastward toward East Pacific and Atlantic Ocean.

By the frequent MJO episode of occurrence over Indonesia Maritime Continent as part the global perspective from the dynamical meteorology and oceanoanography, there was two tropical cyclones formation closer with the Java island namely tropical cyclones "Cempaka" and "Dahlia" during period November 27th, 2017 - December 2nd, 2017 . From the operational point of view, the formation tropical cyclone Cempaka on November 2017 was closer to the coastline of southern Java island causing flash flood, no storm surge over the coast line, land slide, flooding over some areas in central and eastern Java island. Then tropical cyclone Dahlia might cause low storm surge over Sundae Strait and some coastal area over southern west Java Island and strong wind along northern coast of west and central Java Island.

The formation of the unusual Tropical cyclone would be in advance and generating over low latitudes approaching equator line. Then end of the year 2017 up to end January 2018, Indonesia Maritime Continent would suppress the cloud cover and rainfall due to the cooler than normal of the sea surface temperature
Indian ocean west of Indonesia Maritime Continent. Unfortunately during February, activities of the cloud cover and rainfall would be increasing even MJO over Pacific - Atlantic Oceans.

The Cold surge would not encourage the formation the Borneo Vortex, but the convergence zone of northerly and southerly would be part from the Inter Tropical Convergence frequently occurs with more active cloud cover and rainfall. The flooding areas and landside arose including Jakarta and adjoining area frequently occurs with additional condition coolest of the environment most over Java up to lesser of Sundae Island beginning March 2018. Where these meteorological conditions are a little bit anomaly from the normal condition that peak of the rainy season coincide with cooler environment usually be in the end year - beginning next year around December - January/February. In the last that impact from long winter season over northern hemisphere would be in terms of frequently wet, cooled and windy weather, climate and environment condition especially over southern area of Indonesia Maritime Continent and also longer as usual period of the peak rainy season $2017 / 2018$. The dynamical meteorology and oceanography would be interesting in further study if we refer with the global warming and climate change as arising environmental issue starting 1990 up to present time.

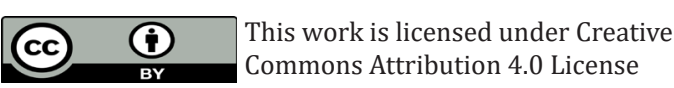

To Submit Your Article Click Here:

Submit Article

DOI: 10.32474/MAOPS.2018.01.000109 